\section{EVALUATION OF EARLY CHILDHOOD BILINGUAL LEARNING \\ ENVIRONMENT AND CHILD DEVELOPMENT}

Evgeniya Shishova, Ph.D., Associate Professor, Department of Educational Psychology,

Kazan (Volga region) Federal University, Russia, evgshishova@yandex.ru

\section{Introduction}

Bilingual education becomes increasingly important having broad perspectives in the modern educational system. Supporters of the sociocultural approach, developmental education (Vygotsky, 1962; Bronfenbrenner, 1993; Galperin, 1969; Davydov, 1995; El'konin, 1972; Veraksa, 2011 and others), and the theory of early bilingual education (Bialystok and Martin, 2004; Protasova, 2003; Gabdulkhakov, 2014; Belyanin, 2004; Bialystok and Shapero, 2005; Goetz, 2003) believe that early second language learning in preschool educational institutions makes sense, as at preschool-age basic personality qualities develop and the foundations are laid for physical, moral and cognitive development. The earlier the child comes into contact with the second language, the higher the child's potential thrives in the future. However, the practices of bilingual competence development provide examples of "semi-lingual" preschool children, the cases when a thought cannot be fully expressed in any language. Such bilingualism inhibits not only speech production in the mother tongue, but also the child's intellectual development in general.

According to Zinchenko, Shaigerova, Dolgikh, and Savelieva, we need to conduct a comprehensive study of the advantages and limitations, associated with the acquisition and usage of two or more languages.

To improve the bilingual development in children and their communicative competence in a multicultural education, we need to create a system of integrated psychological and pedagogical support for the formation of early bilingualism.
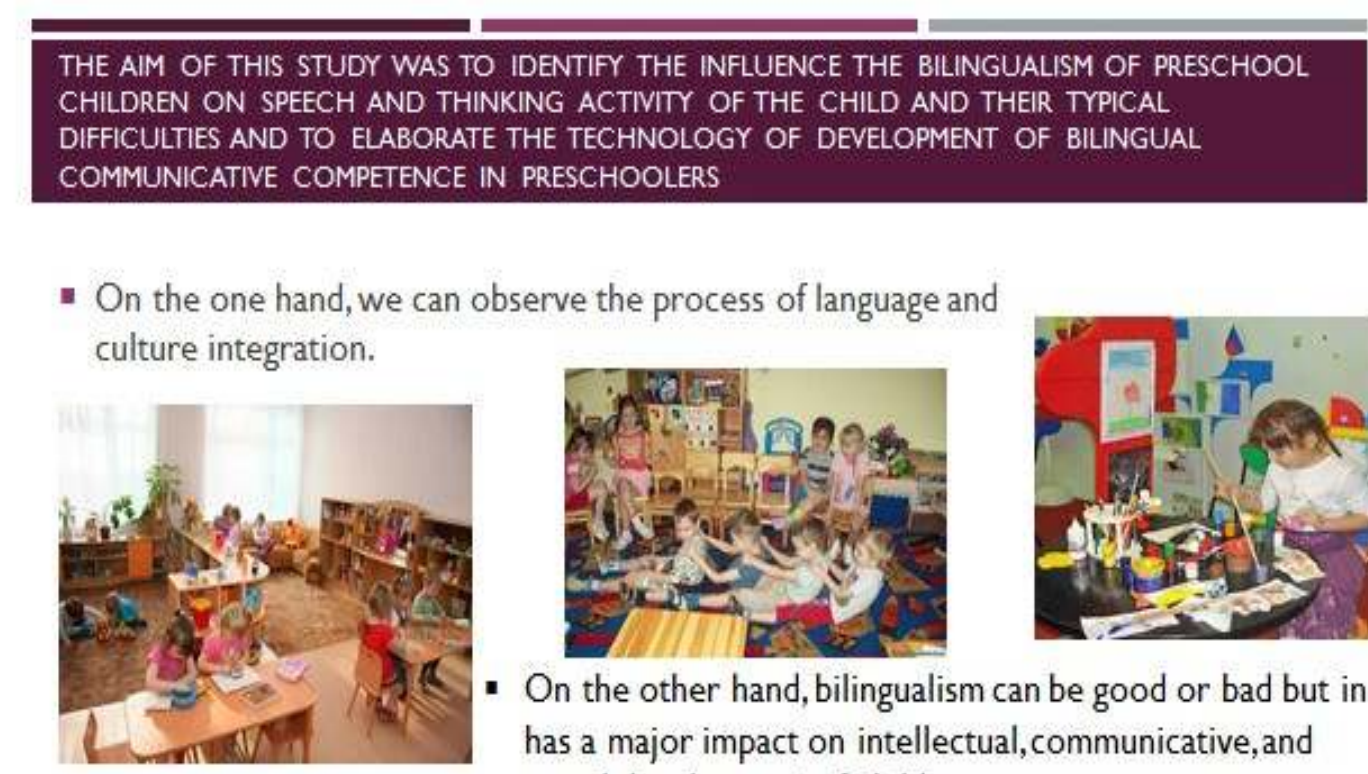

8

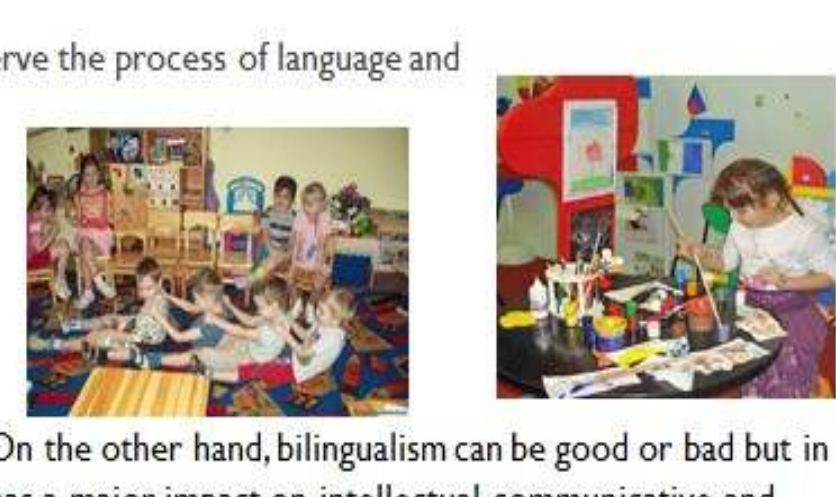

has a major impact on intellectual, communicative, and

moral development of children.

\section{Methodological Framework}

This work is based on the research by Bialystok and Martin (2004), showing that bilinguals outperform monolinguals, the study by Protasova (2003) and the works on a positive impact of bilingualism on the cognitive development (Belyanin, 2009). The analysis of data is based on theoretical foundations of sociocultural theories (Vygotsky, 1962; Bronfenbrenner, 1999).

The research was conducted in the Republic of Tatarstan (part of Russia), mostly populated by the Tatars and Russians. As for the environment of the Republic of Tatarstan, it is reasonable to discuss the issue of bilingualism (the Russian language and the language of the national republic, i.e. the Tartar language) or multilingualism (the Russian, Tartar, and foreign languages). One hundred sixty-five preschoolers (5-to 7year-olds) took part in the survey. They were classified into two groups, Russian-Tatar bilinguals in one group and Russian-speaking monolinguals in other group. The difference between monolinguals (group $A$ ) and bilinguals (group B) was taken into account. The children were tested on well-known measures of executive functions. The preschool teachers filled in observation cards.

\title{
REFERENCES
}

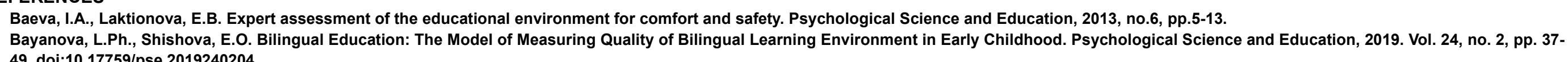

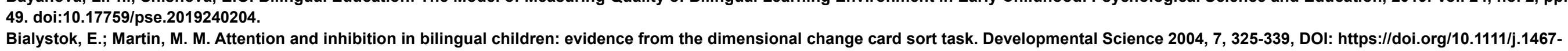
Bialystok, E.; Martin, M. M. Attention and inhibition in bilingual children: evidence from the dimensional change card sort task.
$7687.200 .00531 . x$
Gabdulhakov, V.F. Of linguistic education in kindergartens. International Journal of Early Years Education 2011, 19(2), 185-188. 